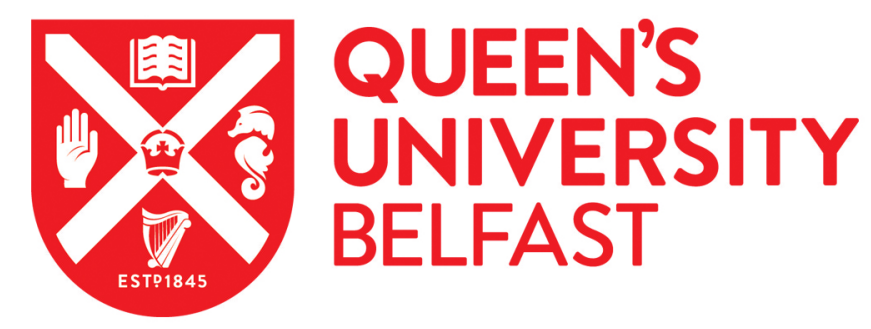

\title{
Climatic controls on Later Stone Age human adaptation in Africa's southern Cape
}

Chase, B. M., Faith, J. T., Mackay, A., Chevalier, M., Carr, A. S., Boom, A., Lim, S., \& Reimer, P. J. (2018).

Climatic controls on Later Stone Age human adaptation in Africa's southern Cape. Journal of Human Evolution, 114, 35-44. https://doi.org/10.1016/j.jhevol.2017.09.006

Published in:

Journal of Human Evolution

Document Version:

Peer reviewed version

Queen's University Belfast - Research Portal:

Link to publication record in Queen's University Belfast Research Portal

\section{Publisher rights}

Copyright 2017 Elsevier

This manuscript is distributed under a Creative Commons Attribution-NonCommercial-NoDerivs License

(https://creativecommons.org/licenses/by-nc-nd/4.0/), which permits distribution and reproduction for non-commercial purposes, provided the author and source are cited.

\section{General rights}

Copyright for the publications made accessible via the Queen's University Belfast Research Portal is retained by the author(s) and / or other copyright owners and it is a condition of accessing these publications that users recognise and abide by the legal requirements associated with these rights.

\section{Take down policy}

The Research Portal is Queen's institutional repository that provides access to Queen's research output. Every effort has been made to ensure that content in the Research Portal does not infringe any person's rights, or applicable UK laws. If you discover content in the Research Portal that you believe breaches copyright or violates any law, please contact openaccess@qub.ac.uk. 
Brian M. Chase*1, J. Tyler Faith ${ }^{2}$, Alex Mackay ${ }^{3}$, Manuel Chevalier ${ }^{1}$, Andrew S. Carr ${ }^{4}$,

5

6 Université Montpellier, Bat.22, CC061, Place Eugène Bataillon, 34095 Montpellier, cedex5, France;

$7 \quad{ }^{2}$ Archaeology Program, School of Social Science, University of Queensland, Brisbane, QLD 4072, Australia;

$8{ }^{3}$ Centre for Archaeological Science, School of Earth and Environmental Sciences, Northfields Avenue, Building

9 41, University of Wollongong, NSW 2522, Australia;

$10 \quad{ }^{4}$ Department of Geography, University of Leicester, Leicester, LE1 7RH, UK;

$11{ }^{5}$ School of Natural and Built Environment, Queen's University Belfast, Belfast, BT7 1NN, Northern Ireland, 12 UK

$14 *$ Correspondence to:

15 Email: brian.chase@univ-montp.fr 


\section{Abstract}

17 Africa's southern Cape is a key region for the evolution of our species, with early symbolic 18 systems, marine faunal exploitation, and episodic production of microlithic stone tools taken 19 as evidence for the appearance of distinctively complex human behavior. However, the temporally discontinuous nature of this evidence precludes ready assumptions of intrinsic

21 adaptive benefit, and has encouraged diverse explanations for the occurrence of these behaviors, in terms of regional demographic, social and ecological conditions. Here, we present a new high-resolution multi-proxy record of environmental change that indicates that

24 faunal exploitation patterns and lithic technologies track climatic variation across the last 2522,300 years in the southern Cape. Conditions during the Last Glacial Maximum and 26 deglaciation were humid, and zooarchaeological data indicate high foraging returns. By contrast, the Holocene is characterized by much drier conditions and a degraded resource base. Critically, we demonstrate that systems for technological delivery - or provisioning were responsive to changing humidity and environmental productivity. However, in contrast

30 to prevailing models, bladelet-rich microlithic technologies were deployed under conditions

31 of high foraging returns and abandoned in response to increased aridity and less productive 32 subsistence environments. This suggests that posited links between microlithic technologies 33 and subsistence risk are not universal, and the behavioral sophistication of human populations 34 is reflected in their adaptive flexibility rather than in the use of specific technological 35 systems.

36 Keywords: paleoclimate; paleoecology; rock hyrax middens; microlithic; macrofauna; 37 Boomplaas Cave 
South Africa's southern coastal margin is a key region for the evolution and development of our species (Ambrose, 2002; Ambrose and Lorenz, 1990; Brown et al., 2012; Henshilwood et al., 2004a; Henshilwood et al., 2002; Marean, 2010; Powell et al., 2009). The southern Cape archaeological record has reframed the debate about the evolution of human behavior, providing early examples of engravings, ornaments, heat treatment of tool-stone and the focussed consumption of marine resources (Delagnes et al., 2016; Henshilwood et al., 2004b; Henshilwood et al., 2002; Henshilwood et al., 2014; Marean, 2014). The region also exhibits regular technological turnover through the last 100,000 years, with the intermittent production of bladelets, bifacial points and backed artefacts and the use of fine-grained rock, interspersed with periods lacking regular retouched flake forms and dominated by locally available rocks such as quartzite and quartz (Deacon, 1984; Wilkins et al., 2017). The links between these variable technological and subsistence records and their environmental context - necessary to arguments about the evolution of human adaptation - remain surprisingly unclear (Deacon, 1982; Roberts et al., 2016). This reflects the region's particular climatic dynamism (Chase and Meadows, 2007) coupled with disagreement concerning the interpretation of its paleoenvironmental archives (e.g. Chase and Meadows, 2007; Deacon and Lancaster, 1988; Faith, 2013b; Marean et al., 2014).

In this paper, we focus on the Later Stone Age record in the southern Cape, for which - in contrast with the Middle Stone Age - high resolution environmental and archaeological data are now available. We explore the strength of coupling between environments, subsistence behavior and lithic technology over the last 22,300 years to understand whether, and how closely, human behavior tracked environmental change. Spanning the transition from the Last Glacial Maximum (LGM; 26.5-19 ka; Clark et al., 2009) to the Holocene (11.7 ka to present Lowe et al., 2008), and episodes of the use of bladelet-rich technological systems, our data also have a bearing on broader debates about the role of what are often termed 'microlithic' technologies in issues of human adaptation and expansion.

\section{Later Stone Age environments and archaeology in the southern Cape}

67 Influenced by both temperate and tropical climate systems (Figure 1), long-term climate change in the southern Cape is characterized by significant and often abrupt fluctuations 
Quick et al., 2015; Quick et al., 2016; Talma and Vogel, 1992). Existing evidence indicates that during the Holocene the relative influences of the two dominant synoptic scale moisturebearing systems -1 ) the southern westerly storm track, which expands/shifts northward in the winter, and 2) the tropical easterly flow, which transports moisture from the Indian Ocean during the summer - have varied significantly (Chase et al., 2013; Chase et al., 2015b). However, there is little detailed paleoenvironmental evidence pre-dating the Holocene (Carr et al., 2016b; Chase and Meadows, 2007), and as a result there are contradictory opinions concerning conditions since the LGM (Chase and Meadows, 2007; Deacon and Lancaster, 1988; Faith, 2013b; Kohfeld et al., 2013; Partridge et al., 1999; Partridge et al., 2004; Sime et al., 2013; Stone, 2014), to the extent that some studies conclude that the region was exceptionally "harsh" and arid during the LGM (Deacon and Lancaster, 1988; Scholtz, 1986), while others infer greater humidity and highly productive terrestrial environments (e.g. Faith, 2013b; Parkington et al., 2000). This uncertainty has fundamentally hindered our understanding of past climate dynamics in the region, and, by extension, the impact of past climate change on hunter-gatherer adaptive and subsistence strategies during both the Later and Middle Stone Age.

In the southern Cape, the Later Stone Age archaeological sequence is typically divided into several industries or technocomplexes: early Later Stone Age (ELSA $\sim 40-24$ cal kBP), Robberg ( 24-12 cal kBP), Oakhurst ( $\sim 12-8$ cal kBP) and Wilton ( $\sim 8-2$ cal kBP), followed by the arrival of Khoikhoi herders in the last 2000 years (Deacon et al., 1984; Deacon, 1978; Lombard et al., 2012; Mitchell, 1988). The ELSA is associated with the production of small flakes, often through bipolar reduction of cores, though it otherwise lacks unifying characteristics and has been described as a period of technological heterogeneity (Mitchell, 1988; Wadley, 1993). The Robberg presents more coherent characteristics, including the production of large numbers of bladelets (small, elongate flakes usually less than $24 \mathrm{~mm}$ long) produced both from dedicated bladelet cores and from those worked by bipolar reduction (Mitchell, 1988). The Robberg also sees more concentrated, if episodic, use of fine-grained rocks such as a silcrete and chert than the preceding or subsequent phases (Deacon, 1978; Deacon, 1982). The Oakhurst (or Albany) is typified by fewer bladelets, larger flakes, a range of scraper forms and declining use of fine-grained rock, while the Wilton features both scrapers and backed artefacts and highly variable patterns of raw material use (Deacon, 1972; Deacon, 1978; Lombard et al., 2012). While these units are 
coarse and mask considerable variation, they provide a useful heuristic for discussing broad patterns in technological change across the later LSA.

Consistent with the imprecise meaning of the term (Pargeter, 2016), the ELSA, Robberg and Wilton have all been described as 'microlithic' (Bousman, 2005; Deacon, 1984; Mitchell, 1988; Wadley, 1993), but based on different characteristics - small flakes in the case of the ELSA, bladelets in the case of the Robberg and backed artefacts in the Wilton (Lombard et al., 2012). The advent of dedicated bladelet production in particular - as characterizes the Robberg - is argued to have presented humans with a significant adaptive advantage during our evolution and dispersal (Ambrose, 2002; Bar-Yosef and Kuhn, 1999;

111 Clarkson et al., 2009; Foley and Lahr, 2003). Some researchers have linked an emphasis on

112 bladelet production with responses to heightened subsistence risk associated with low or 113 declining subsistence resource productivity (Elston and Brantingham, 2002; Petraglia et al., 114 2009) (for discussion of the risk concept used here see Bamforth and Bleed, 1997). Others

115 have suggested that bladelet production provided benefits under conditions of high residential 116 mobility (Goebel, 2002; Neeley, 2002). Both explanations - increased subsistence risk and increased mobility - have been posited for bladelet-rich systems in southern Africa during

118 globally cooler conditions (Ambrose, 2002; Grosjean et al., 2003; McCall, 2007; McCall and 119 Thomas, 2012; Mellars, 2006; Mitchell, 2000). The Robberg specifically has been associated 120 with increased residential mobility in response to inferred diminishing resource density 121 (Ambrose, 2002; Mitchell, 2000), and has been explained as a risk-dampening response to 122 resource stress (Mackay, 2009). Other researchers, however, have suggested that any tracking 123 between LSA technological systems and paleoenvironmental variation was relatively weak, and occurred only at the broadest scale of environmental change (e.g. Deacon, 1982). The reality of coupling between technology, subsistence conditions and environmental change in this period is thus contested, and with it the viability of high-order explanations for the behavioral significance of artefacts such as bladelets.

\section{Sites and regional setting}

129 To explore the relationship between environmental change and human activities and 130 technology, we focus on sites from the Swartberg mountains of South Africa's southern 131 Cape, one of the major ranges in the east-west axis of the Cape Fold Mountains (Figure 1). 132 From Seweweekspoort, a deep transversal valley in the central Swartberg mountains, a series 133 of rock hyrax (Procavia capensis) middens - stratified accumulations of dried urine and fecal 
134 pellets (see Chase et al., 2012) - were identified, and six middens from two sites, 135 Seweweekspoort-1 (SWP-1; 33.3668 ${ }^{\circ}$ S, 21.4144 ${ }^{\circ} \mathrm{E}$ ) and Seweweekspoort-3 (SWP-3; $13633.4092^{\circ} \mathrm{S}, 21.4031^{\circ}$ ), were analysed for this study. SWP-1 is located on a west-facing cliff 137 on the northern slope of the pass (Figure 1). The SWP-1 middens were taken from several 138 locations within the same larger shelter, formed by a $\sim 100 \mathrm{~m}$ overhanging cliff. SWP-3 is 139 located on a low eastern cliff in the central section of the valley near the valley bottom, and 140 experiences a more humid microclimate relative to the exposed position of SWP-1.

The SWP-1 site is located in the North Swartberg Sandstone Fynbos, but less than a kilometre to the north is the Matjiesfontein Shale Renosterveld (Mucina and Rutherford, 2006). The former, depending on altitude and aspect, is predominantly asteraceous, proteoid and restioid fynbos, while the latter is dominated by asteraceous elements, particularly Elytropappus rhinocerotis, Eriocephalus sp. and Euryops sp., and by an increasing number of succulents, primarily from the Crassulaceae family (Mucina and Rutherford, 2006). At SWP1 , these vegetation types inter-digitate to some extent, with the broad west-facing drainage just north of the site supporting more hydrophilic taxa, such as Protea. The north-facing rock shelves directly adjacent to the site maintain only shallow soils and a dominance of succulents. Grasses in the region are a mixture of $\mathrm{C}_{3}$ (e.g., Erharta) and $\mathrm{C}_{4}$ (e.g., Aristida,

154 Stipagrostis) varieties (http://sibis.sanbi.org/faces/DataSources.jsp; Rutherford et al., 2012;

155 Rutherford et al., 2003; SANBI, 2003). SWP-3 is located in the South Swartberg Sandstone

156 Fynbos, which at the site is primarily proteoid in character. In addition, there are numerous 157 arboreal/Cape thicket elements (e.g., Podocarpus, Celastraceae, Dodonaea, Searsia, Euclea, Oleaceae) associated with drainages and the nearby riparian zones of the valley bottom.

The Seweweekspoort sites are located $70 \mathrm{~km}$ west of the well-stratified late

160 Pleistocene / Holocene archaeological site of Boomplaas Cave. This site is also situated on 161 the flanks of the Swartberg and occupies a very similar climatic regime, making it ideal for 162 exploring linkages between climate, environment, subsistence and technology at high 163 temporal resolution. Located on the southern flanks of the Swartberg range overlooking the 164 Cango Valley, Boomplaas Cave was excavated by Hilary Deacon in the 1970s (Deacon, 
1979). The excavated sediments were divided into a series of members, some of which were subdivided into units. The site is positioned within a transitional shrubland whose component species vary as a function of temperature and moisture gradients moving upslope from the floor of the valley (Vlok and Schutte-Vlok, 2010). The lowlands to the south are characterized by renosterveld habitats, which give way to fynbos vegetation along the slopes of the Swartberg. Along watercourses and ravines in the Cango Valley are more densely wooded habitats that include sweet thorn trees (Vachellia (Acacia) karroo) and ironwood (Olea spp.) among others (Moffett and Deacon, 1977). As is also the case at Seweweekspoort, Boomplaas today receives contributions of both winter and summer rainfall

174 (Figure 1). Thus, the limited grasses that do occur in the area today include a mixture of both $175 \mathrm{C}_{3}$ and $\mathrm{C}_{4}$ species.

\section{Materials and methods}

177 Rock hyrax middens accumulate over thousands of years and preserve continuous records of past climate change (Chase et al., 2012). The six middens from Seweweekspoort sites SWP-1 and SWP-3 were selected for analysis because they are composed almost entirely of hyraceum (no visible fecal pellets). Our experience suggests that such middens have superior stratigraphic integrity compared to more pellet-rich middens. Representative portions of the middens were processed as described in Chase et al. (2013; 2012). Radiocarbon age determinations $(n=36)$ were processed at the ${ }^{14}$ CHRONO Centre, Queen's University Belfast using accelerator mass spectrometry (AMS) (Supplementary Online Material [SOM] Figure $\mathrm{S} 1$; Table S1). The radiocarbon ages were corrected for isotope fractionation using the AMS measured $\delta^{13} \mathrm{C}$ and calibrated using the SHCal13 calibration data (Hogg et al., 2013). The Bacon 3.0.3 software package (Blaauw and Christen, 2011) was used to generate all agedepth models (SOM Figure S1). Results indicate that these sequences continuously span the last 22,300 years.

The fossil pollen content of 82 adjacent, contiguous pollen samples were prepared with standard physical (600 $\mu \mathrm{m}$ sieving and decanting) and chemical $(\mathrm{HCl}, \mathrm{KOH}, \mathrm{HF}$ and acetolysis) methods (Moore et al., 1991). Lycopodium tablets were added to the weighed sample to estimate pollen concentrations (Stockmarr, 1971). A minimum pollen sum of 400

194 grains was counted at a magnification of $\times 400$ under a light microscope, and identified with 195 the help of the literature (Scott, 1982; van Zinderen Bakker, 1953, 1956; van Zinderen 
196 Bakker and Coetzee, 1959), and photographic and slide reference collections at the

197 Universities of the Free State, Cape Town, and Montpellier.

The bulk stable nitrogen $\left({ }^{15} \mathrm{~N}\right)$ and carbon $\left({ }^{13} \mathrm{C}\right)$ isotope contents of 767 overlapping hyraceum samples were measured at the Department of Archaeology, University of Cape Town following Chase et al. (2010; 2009; 2011; 2012), with contiguous/overlapping samples obtained from two series of offset $1 \mathrm{~mm}$ holes. For the stable isotope analyses, the standard deviation derived from replicate analyses of homogeneous material was better than $0.2 \%$ for both nitrogen and carbon. Nitrogen isotope results are expressed relative to atmospheric nitrogen (SOM Figure S2). Carbon isotope results are expressed relative to Vienna PDB (SOM Figure S3).

Stable isotope results from the different Seweweekspoort rock hyrax middens were combined into a single aggregate record using Local Regression (LOESS) curve fitting of the combined datasets (SOM Figures S2 and S3). As individual middens under the same climate regime may exhibit differences in their isotopic records due to microclimatic influences on individual foraging ranges (i.e., baseline $\delta^{15} \mathrm{~N}$ variability), we have adjusted the $\delta^{15} \mathrm{~N}$ to account for these differences prior to LOESS curve fitting. Using the SWP-1-1 and SWP-1$4 \mathrm{~b}$ records as a datum, an estimated offset of $1.5 \%$ was added to the $\delta^{15} \mathrm{~N}$ data from the SWP-3-1 to compensate for the more humid microclimate in which the midden was found, and $0.5 \%$ and $1 \%$ were added to SWP-1-5 and SWP-1-2a respectively to account for their more exposed positions.

The carbon isotopic composition of the hyraceum is representative of vegetation around a midden site (Carr et al., 2016a) and provides information on 1) the relative contribution of $\mathrm{C}_{3}, \mathrm{C}_{4}$ and CAM plants (Smith, 1972) to the animals' diet, and 2) variations in

219 plant water-use efficiency (WUE) as a function of climate (Ehleringer and Cooper, 1988;

220 Farquhar et al., 1989; Farquhar and Richards, 1984; Pate, 2001). Throughout the broader region, the distribution of $\mathrm{C}_{3}$ and $\mathrm{C}_{4}$ grasses tracks the proportion of winter versus summer rainfall (Vogel, 1978). As mentioned, at Seweweekspoort today, grasses are a mosaic of $\mathrm{C}_{3}$ and $\mathrm{C}_{4}$ varieties (Rutherford et al., 2012; Rutherford et al., 2003; SANBI, 2003), and where aspect and soil depth limit soil water content, CAM plants become increasingly abundant. As $\mathrm{C}_{3}$ plants are depleted in ${ }^{13} \mathrm{C}$ compared with most $\mathrm{CAM}$ and all $\mathrm{C}_{4}$ plants, higher $\delta^{13} \mathrm{C}$ values indicate more abundant warm season $\left(\mathrm{C}_{4}\right)$ grasses and/or succulent plants (CAM), and generally warmer/more arid conditions. 
Hyraceum $\delta^{15} \mathrm{~N}$ is an indicator of changes in ecosystem water-availability (Carr et al., 2016a; Chase et al., 2013; Chase et al., 2015b; Chase et al., 2009; Chase et al., 2011). A positive relationship exists between aridity and $\delta^{15} \mathrm{~N}$ in soils, plants and herbivores, with drier conditions correlating with enriched $\delta^{15} \mathrm{~N}$ (Carr et al., 2016a), most likely as a result of denitrification processes in arid/semi-arid soils (Handley et al., 1999; Handley et al., 1994; Hartman, 2011; Heaton, 1987; Murphy and Bowman, 2006, 2009; Wang et al., 2010). In the hyraceum samples, the narrowly defined feeding range of the hyraxes ( $<60 \mathrm{~m}$; Sale, 1965), and the accumulation rates of the middens ( $\sim 20-60$ years/sample) enforce a spatio-temporal averaging that reduces the $\delta^{15} \mathrm{~N}$ variability observed in modern ecosystem studies (Carr et al., 2016a), and provides a more reliable index of past water variability (Carr et al., 2016a; Chase et al., 2012).

\section{Boomplaas faunal and archaeological archives}

240 The Boomplaas sequence spans much of the last $>65,000$ years (Deacon, 1982), though we focus here on the fauna and flaked stone artifacts from the upper stratigraphic units corresponding in age with the Seweweekspoort record (SOM Table S2). We use these data to explore the relationship between the paleoenvironmental changes documented at

244 Seweweekspoort and mammal community composition, foraging efficiency, and technological organization. Ages for Boomplaas follow Deacon (1982), calibrated using SHCal13 (Hogg et al., 2013). These published data do present limitations, as they do not adequately bracket each stratigraphic unit. In an effort to maximize their utility, and estimate likely intervals of time that each unit may represent, we derived depths from the published stratigraphic diagrams and calculated a general age-depth model for the sequence. While apparently quasi-continuous, with a relatively constant depositional rate, the nature of the sequence, in terms of lithology, suggests more sporadic deposition. In plotting each unit, we have included both minimum and maximum weighted mean ages as well as potential minimum and maximum ages of the units considering potential sources of error related to radiocarbon calibration and assumptions of accumulation rates (SOM Figure S4). This highlights the clear need to initiate a systematic revision of the chronologies of many archaeological sites in the region (e.g. Loftus et al., 2016; Sealy et al., 2016) to enable more robust inter-site and inter-regional comparisons.

Taxonomic abundances (number of identified specimens: NISP) of ungulates from Boomplaas Cave were derived from Faith (2013a), with Klein's (1983) specimen counts used 
for the uppermost member DGL. Comparable data (minimum number of individuals: MNI) 261 for the Boomplaas microfauna were derived from Avery (1982). To facilitate comparison with the SWP record, we conducted a detrended correspondence analysis (DCA) for both data sets, using the first axis (rescaled from 0 to 100) to broadly summarize faunal composition (Figure 3 ). The linear trends in both taxonomic groups closely parallel a decline in ungulate grazers (Figure 3), suggesting that the DCA axis 1 scores are related to the replacement of grasslands by more shrubby habitats (see also Faith, 2013a). Broadly parallel changes are also observed in the south coast faunal sequences from Nelson Bay Cave (Klein, 1983) and Byneskranskop 1 (Schweitzer and Wilson, 1983) (Figure 1), implying regional shifts in habitat structure.

Humans are the primary accumulator of the Boomplaas Cave macrofauna from stratum CL4 and above (Faith, 2013a; see also Faith, 2011). This allows us to explore how the environmental changes documented at SWP translate to changes in foraging efficiency. Based on models grounded in optimal foraging theory, we examine two zooarchaeological indicators of foraging efficiency. These include the relative abundance of small-bodied and presumably low-ranked prey (leporids and tortoises) and the average food utility index (FUI; Metcalfe and Jones, 1988) - a proxy for energetic returns (e.g., meat, fat, marrow) of various ungulate body parts - of large mammal (size classes 3 and 4: 84 to $900 \mathrm{~kg}$ ) skeletal elements (data from Faith, 2011b). Given the evidence for attrition at Boomplaas Cave (Faith and Thompson, in press), we follow Cleghorn and Marean's (2004) taphonomic model of bone survivorship and restrict analysis to the long-bones (femur, tibia, humerus, radius, and metapodials) and skull elements (crania and mandibles). Building on previous studies conducted elsewhere (e.g., Grayson, 1991, 2005; Broughton, 1994, 1999; Cannon, 2003;

283 Faith, 2007; Munro 2004; ), we predict that declining foraging efficiency will be 284 characterized by (1) increasing frequencies of low-ranked prey, reflecting declining availability of high-ranked prey (e.g., large game) on the landscape, and (2) increasing mean FUI values, reflecting intensified field processing due to an increase in carcass transport distances and/or search times. We recognize that because tortoises are slow-moving and easily captured, they might be considered a high-ranked prey type that should be collected whenever encountered (e.g. Stiner et al., 2000). However, the significant positive correlation between their abundances and those of leporids (Spearman's $\rho: r_{s}=0.814, p \leq 0.001$ ), which 
are unequivocally a low-ranked prey type, suggests that we can treat tortoises as low-ranked prey in this context.

All lithic data are taken from Deacon (1982), standardized to site mean (standardized value $=($ layer value - site mean) / site standard deviation). We focus on the abundance of bladelets (Figure 3d), and three indicators of technological delivery: ratio of cores to retouched flakes (Figure 3g), total proportions of retouched flakes (Figure 3e), and artefact density measured as total number of artefacts per bucket of excavated sediment following Deacon (1982) (Figure 3h). These last three values function, respectively, as proxies for the transport of retouched flakes vs tool-making potential (mode of technological 'provisioning' (Kuhn, 1995)), frequency of flake curation, and intensity of site-use (Barton and RielSalvatore, 2014; Kuhn and Clark, 2015; Parry and Kelly, 1987; Riel-Salvatore and Barton, 2004). Provisioning, which we define as the systems by which stone artefact technologies are delivered in anticipation of future needs, has been argued to mediate the response of mobility to environmental change (Mackay et al., 2014; Wilkins et al., 2017). Under conditions of diminished residential mobility, we expect increases in core transport and artefact density, and lower rates of curation. The inverse is expected when mobility increases and the scheduling of movements becomes harder to predict. If bladelets are a response to

311 diminishing subsistence returns, then their abundance should track humidity and resource

312 productivity inversely. Similarly, if bladelets are positively associated with increasing

313 residential mobility and declining durations of site occupancy then we expect an inverse 314 relationship with artefact density. We also consider the relative abundance of spatially-rare, 315 fine-grained rocks such as silcrete and crypto-crystalline silicates (CCS, subsuming chert and 316 chalcedony) (Figure 3f); it has recently been shown that the abundance of rocks such as 317 silcrete is responsive to increases in overall artefact abundance (Will and Mackay, 2016), and

318 may thus reflect diminished residential mobility and improved scheduling of movements.

\section{Results}


321 The Seweweekspoort record shows substantial changes in both $\delta^{13} \mathrm{C}$ (range 5.1\%o) and $\delta^{15} \mathrm{~N}$ 322 (range 9.5\%o) over the last 22,300 years, implying significant changes in vegetation and 323 climate (Figure 2). These changes are coherent with the pollen data from the same material. 324 Across this period, a strong first-order trend is apparent, with cool, humid glacial conditions 325 (indicated by increased cryophilic Fynbos Biome vegetation pollen and lower $\delta^{13} \mathrm{C}$ and $\delta^{15} \mathrm{~N}$ ) 326 transitioning into warmer, but substantially drier conditions during the Holocene (declining 327 fynbos pollen and higher $\delta^{13} \mathrm{C}$ and $\delta^{15} \mathrm{~N}$; Figure 2). This aridification coincides with the 328 deglacial decline in Antarctic sea-ice extent (using sea-salt sodium as a proxy) between 19-11 ka (Fischer et al., 2007; Levine et al., 2014; Wolff et al., 2010) (Figure 2), which is considered to be a strong determinant on the position of the westerly storm track (Bard and Rickaby, 2009; Stuut et al., 2004). The elevated grass pollen percentages during the last glacial period, coupled with low $\delta^{13} \mathrm{C}$ suggest the increased prevalence of cool growing season $\mathrm{C}_{3}$ grasses (Vogel, 1978), consistent with the model that much of the precipitation during this period fell during the winter months as a result of increased westerly influence. While recent work has indicated that variability in summer rainfall may have had some significant impact in the winter rainfall zone (Chase et al., 2015a; Chase et al., 2015b), longterm (i.e., glacial-interglacial timescales) precipitation trends in the summer rainfall zone (Chevalier and Chase, 2015) exhibit a clear antiphase relationship with humidity at Seweweekspoort (Figure 2), indicating that tropical systems played a limited role in the region at these timescales.

Within this broad first-order trend of deglacial aridification at Seweweekspoort, significant second-order abrupt episodes of wetter conditions (centred at 14.5, 11 and 4 cal $\mathrm{kBP}$, and the last millennium) indicate major reorganisations of regional climate dynamics. In southern Africa, where rainfall regimes are defined by their strong seasonality, the varying contribution of the non-dominant moisture-bearing system can have a substantial impact on regional environments, shortening or attenuating the impact of often pronounced drought seasons (Chase et al., 2015a). In this context, humid episodes within the last glacialinterglacial transition (LGIT; 18.5-11.7 ka) - previously identified as being a period of exceptionally high effective precipitation in the region (Scholtz, 1986) - can be linked to the 
warming of both high southern latitudes (Stocker, 1998; Stocker and Johnsen, 2003) and the oceans surrounding southwestern Africa (Barker et al., 2009; Farmer et al., 2005; Kim and Schneider, 2003), including a response to the slow-down of Atlantic Meridional Overturning Circulation (AMOC) during Heinrich stadial 1 (HS1; 18-14.6 ka) (McManus et al., 2004) (Figure 2).

While the influence of the westerly storm track may have diminished as the Subtropical Front shifted poleward (Barker et al., 2009), increased evaporation from warmer oceans and the invigoration of the southern African monsoon system would have augmented the summer rain component in what was then primarily a winter rainfall regime, reducing rainfall seasonality and drought stress. At Seweweekspoort, peaks in humidity at 14.5 and 11 cal kBP typify this, with reductions in fynbos vegetation under slightly warmer conditions, and with increased grass cover as a function of more regular rains promoting shallow rooting vegetation. With the onset of the Holocene, as warming continued, the combination of tropical and temperate systems that resulted in these phases of LGIT humidity broke down. Changes in global boundary conditions resulted in 1) a more permanent southerly position of the westerly storm track, and less winter rain, and 2) strong regional warming that intensified potential evapotranspiration, enhancing drought stress (Chevalier and Chase, 2016). Combined, these factors are interpreted to have driven the marked aridification exhibited in the Seweweekspoort records (Figure 2).

\section{Changing resources and technology}

The climatic changes robustly identified at Seweweekspoort are strongly reflected in our newly synthesised faunal and archaeological records (Figure 3). Large mammals and microfauna from Boomplaas Cave indicate open and grassy environments during the LGM, giving way to shrublands across the Pleistocene-Holocene transition; a phase marked by large mammal extinctions and shifts in faunal community composition throughout the region (Faith and Behrensmeyer, 2013). These changes are evident in the DCA axis 1 scores (Figure 3). The abundance of ungulate grazers and axis 1 scores at the site closely tracks $\delta^{13} \mathrm{C}, \delta^{15} \mathrm{~N}$ (Figure 3), and changes observed in the pollen record at Seweweekspoort (Figure 2). Likewise, the carbon isotope composition of tooth enamel from Boomplaas grazers parallels the $\delta^{13} \mathrm{C}$ shifts at Seweweekspoort, with predominantly $\mathrm{C}_{3}$ grasses consumed during the LGM giving way to increased $\mathrm{C}_{4}$ grasses during the LGIT (Sealy et al., 2016). 
These findings contrast with earlier interpretations from floral (Deacon et al., 1984; Scholtz, 1986) and faunal assemblages (Avery, 1982; Klein, 1972; Klein, 1980, 1983) from southern Cape archaeological sequences, wherein open grassland environments - inferred primarily from a predominance of grazers in large mammal fossil records - were interpreted as signs of increased aridity. Our results support inferences that evidence for grassier vegetation indicates the influence of more/more regular precipitation on the richer soils of the valleys and plains of the southern Cape (Chase, 2010; Faith, 2013b), which currently support relatively xeric karroid vegetation (Cowling, 1983). In contemporary African ecosystems, elevated precipitation is typically associated with increased biomass of large herbivores (Coe et al., 1976; East, 1984), a phenomenon likely to have been enhanced by increased plant nutrient content under reduced atmospheric $\mathrm{CO}_{2}$ concentrations (Faith, 2011a). The implication for human populations is that cooler, more humid late Pleistocene conditions presented a more productive resource base, including the proliferation of large grazing ungulates.

Zooarchaeological evidence from the human-accumulated vertebrate assemblages at Boomplaas Cave (CL4 and above) indicates that aridification through the LGIT is associated with a decline in foraging efficiency. Across the LGIT (CL4 to BRL5), tortoises and leporids increase in abundance relative to ungulates (tortoises: $\chi^{2}$ trend $=90.332, p<0.001$; leporids: $\chi^{2}$ trend $\left.=64.854, p<0.001\right)$. Because ungulates are larger and provide greater energetic returns than tortoises or hares - in which case they should be pursued whenever encountered - these trends imply a decline in their abundances on the landscape. This is also reflected in changes in carcass transport strategies. The average food utility index of large mammal high-survival skeletal elements increases steadily across the LGIT (Spearman's rho $=0.964, p<0.001$ ), indicating a greater emphasis on skeletal parts providing the highest energetic returns. Within an optimal foraging framework, this trend is consistent with an increase in carcass transport

412 distances and/or search times stemming from diminished availability of large game (Cannon, 413 2003; Faith, 2007). These parallel trends imply that the cooler and more humid conditions of 414 the late Pleistocene provided a more productive vertebrate resource base with higher average energetic returns than did the more arid conditions of the early Holocene. 
The decline in foraging efficiency through the deglaciation reverses through the

417 Holocene. Barring an increase observed in the two upper units (Table 1), leporids decline in 418 abundance relative to ungulates after the peak in BRL5 $(\sim 11-12 \mathrm{cal} \mathrm{kBP})\left(\chi^{2}\right.$ trend $=15.854, p<$ 419 0.001). This trend, which is consistent with an increase in ungulate abundances on the 420 landscape, complements a decline in the mean FUI of large mammal skeletal parts $421 \quad($ Spearman's rho $=0.821, p=0.034)$.

From the LGM through the Holocene, there are marked temporal trends in lithic indicators of technological systems at Boomplaas Cave (Figure 3). Though not without some variation, there is a general decline through time in the abundance of bladelets $\left(\chi^{2}\right.$ trend $=$ 1323.693, $p<0.001)$, cores relative to retouched flakes $\left(\chi^{2}\right.$ trend $\left.=921.328, p<0.001\right)$, and fine-grained raw materials $\left(\chi^{2}\right.$ trend $\left.=775.322, p<0.001\right)$, coupled with an increase in the frequency of retouched pieces $\left(\chi^{2}\right.$ trend $\left.=1510.282, p<0.001\right)$. A relationship between technological systems and the environment is suggested by strong correlations between these indicators and the DCA axis 1 scores derived for both ungulates and microfauna (Figure $3 b$, c; Table 2). Indeed, all the measures of technological change we employ for the Boomplaas assemblage are significantly correlated with changes in ungulate community composition, and most with the composition of micromammal communities (Table 2). Both sets of axis 1 scores track changing frequencies of grassland indicators at the site, as well as the $\delta^{15} \mathrm{~N}$ and especially $\delta^{13} \mathrm{C}$ values from Seweweekspoort (Figure 3). It follows that technological change is tracking environmental change, including the patterns of climate-driven environmental change documented in the Seweweekspoort records.

During the LGM and early LGIT bladelets are abundant and artefact indicators are consistent with low residential mobility (Figure 3). With the exception of the earliest LGM members (GWA/HCA), for which taphonomic data suggest limited human occupation (Faith, 2013a), artefact densities are well above the overall mean at Boomplaas, flake curation is uncommon, and all core to retouched flake values pre-13 ka (CL member units) are higher than all those that follow. Associated high frequencies of rock such as silcrete and CCS before 12 cal $\mathrm{kBP}(\mathrm{CL}+\mathrm{BRL} 7)$ imply regular and predictable access to fine-grained rock 
through this period (Figure 3). These factors combined imply an emphasis on the transport of tool-making potential to sites.

Coincident with the onset of the first-order aridification trend after $\sim 14$ ka (BRL member units), artefact densities decrease, as do proportions of fine-grained rock and bladelets. The period is broadly characterised by more common acquisition and reduction of readily available local rocks (quartz and quartzite), with diminishing intensity of site use and little transport of cores or curation of flakes. Investment in technological costs in the later LGIT appears minimal and may reflect greater allocation of energy to search and handling of subsistence packages in response to diminishing ungulate abundance (cf., Hames, 1992; Mackay and Marwick, 2011). From the beginning of the Holocene (BRL3 through to DGL member), and tracking diminishing humidity, artefact densities are low and locally abundant rock continues to dominate, but flake curation becomes markedly more common technological systems show a much greater emphasis on transportation and maintenance of implements in this period than in the Pleistocene.

\section{Conclusions}

The findings presented here overturn prevailing models of environmental and behavioral change in Africa's southern Cape. A continuous and high-resolution environmental base-line is provided for the first time, indicating a trend from relative humidity during the LGM to increased aridity during the Holocene, with marked shifts in moisture across the LGIT. Rather than being characterised by 'harsh,' conditions (Deacon and Lancaster, 1988; Scholtz, 1986), the mesic environments of the late Pleistocene were highly productive, with more extensive grasslands existing in areas now dominated by drought resistant succulent shrublands. Zooarchaeological data indicate proliferation of a diverse ungulate grassland community during this time, suggesting greater resource availability for humans living in the area, and reduced search and handling times for large game. While lithic technologies track these changes, we found no evidence to support an association between the production of bladelets during the LGM/early LGIT (Robberg) and diminished subsistence conditions.

474 Indeed, bladelets seem to have flourished in a period of relative resource abundance. The period of lowest subsistence productivity inferred from the Seweweekspoort data probably occurred during the Holocene, associated with aridification and the concomitant loss of large ungulates and faunal diversity recorded at Boomplaas. This change led to increases in carcass processing at kill sites, as evidenced by more selective transport of high utility body parts, 
479 increased reliance on low-ranked prey, and a technological response in which flakes from 480 locally acquired rocks were curated, core transportation was relatively rare, and bladelets 481 were uncommon. In documenting the strong coupling of environmental, subsistence and 482 technological behavior in Later Stone Age foragers, our data reflect the simple observation 483 that all lithic technologies can be adaptive solutions, not only those often assumed to provide 484 particular adaptive benefits. The findings afforded by high resolution analysis of late 485 Pleistocene and Holocene climate imply more generally that the lack of certain kinds of 486 technologies - such as bladelets, backed artefacts and bifacial points - in the earlier stages of 487 human evolution need not carry inherent meaning. The ability of foragers to track rapid 488 climatic and environmental changes with adaptive cultural responses is a better arbiter of 489 cognitive complexity than the deployment of any specific technological system. 
491 Funding was received from the European Research Council (ERC) under the European

492 Union's Seventh Framework Programme (FP7/2007-2013)/ERC Starting Grant "HYRAX", 493 grant agreement no. 258657, and the International Union for Quaternary Research (INQUA), 494 project no. 1205P. We would like to thank Matthew Britton and Ian Newton for assistance in collecting and analysing the material.

\section{References}

497 Ambrose, S.H., 2002. Small things remembered: origins of early Microlithic industries in 498 Sub-Saharan Africa, in: Elston, R.G., Kuhn, S.L. (Eds.), Thinking Small: Global Perspectives on Microlithization. American Anthropological Association, pp. 9-30.

500 Ambrose, S.H., Lorenz, K.G., 1990. Social and ecological models for the Middle Stone Age 501 in Southern Africa, in: Mellars, P. (Ed.), The Emergence of Modern Humans. Edinburgh 502 University Press, Edinburgh, pp. 3-33.

503 Avery, D.M., 1982. Micromammals as palaeoenvironmental indicators and an interpretation 504 of the late Quaternary in the southern Cape Province, South Africa. Ann. S. Afr. Mus. 85, 505 183-377.

506 Bamforth, D.B., Bleed, P., 1997. Technology, flaked stone technology, and risk, in: Clark, 507 G.A. (Ed.), Rediscovering Darwin: Evolutionary Theory in Archaeology. American 508 Anthropological Association, Washington, pp. 109-140.

509 Bar-Yosef, O., Kuhn, S.L., 1999. The big deal about blades: Laminar technologies and 510 human evolution. Amer. Anthrop. 101, 322-338.

511 Bard, E., Rickaby, R.E.M., 2009. Migration of the subtropical front as a modulator of glacial 512 climate. Nature 460, 380-383.

513 Barker, S., Diz, P., Vautravers, M.J., Pike, J., Knorr, G., Hall, I.R., Broecker, W.S., 2009. 514 Interhemispheric Atlantic seesaw response during the last deglaciation. Nature 457, $1097-$ 5151102.

516 Barton, C.M., Riel-Salvatore, J., 2014. The formation of lithic assemblages. J. Archaeol. Sci. 517 46, 334-352.

518 Blaauw, M., Christen, J.A., 2011. Flexible Paleoclimate Age-Depth Models Using an 519 Autoregressive Gamma Process. Bayesian Analysis 6, 457-474.

520 Bousman, C.B., 2005. Coping with risk: Later stone age technological strategies at 521 Blydefontein Rock Shelter, South Africa. J. Anthrop. Archaeol. 24, 193-226.

522 Brown, K.S., Marean, C.W., Jacobs, Z., Schoville, B.J., Oestmo, S., Fisher, E.C., Bernatchez, 523 J., Karkanas, P., Matthews, T., 2012. An early and enduring advanced technology originating 524 71,000 years ago in South Africa. Nature 491, 590-593.

525 Cannon, M.D., 2003. A model of central place forager prey choice and an application to 526 faunal remains from the Mimbres Valley, New Mexico. J. Anthrop. Archaeol. 22, 1-25. 
Carr, A.S., Chase, B.M., Boom, A., Medina-Sanchez, J., 2016a. Stable isotope analyses of rock hyrax faecal pellets, hyraceum and associated vegetation in southern Africa: Implications for dietary ecology and palaeoenvironmental reconstructions. J. Arid Environ. $530134,33-48$.

Carr, A.S., Chase, B.M., Mackay, A., 2016b. Mid to Late Quaternary Landscape and Environmental Dynamics in the Middle Stone Age of Southern South Africa, in: Stewart, B.A., Jones, S. (Eds.), Africa from Stages 6-2: Population Dynamics an Palaeoenvironments. Springer.

535 Chase, B.M., 2010. South African palaeoenvironments during marine oxygen isotope stage 4: a context for the Howiesons Poort and Still Bay industries. J. Archaeol. Sci. 37, 1359-1366.

Chase, B.M., Boom, A., Carr, A.S., Carré, M., Chevalier, M., Meadows, M.E., Pedro, J.B.,

538 Stager, J.C., Reimer, P.J., 2015a. Evolving southwest African response to abrupt deglacial 539 North Atlantic climate change events. QSRv 121, 132-136.

540 Chase, B.M., Boom, A., Carr, A.S., Meadows, M.E., Reimer, P.J., 2013. Holocene climate 541 change in southernmost South Africa: rock hyrax middens record shifts in the southern westerlies. QSRv 82, 199-205.

543 Chase, B.M., Lim, S., Chevalier, M., Boom, A., Carr, A.S., Meadows, M.E., Reimer, P.J., 2015b. Influence of tropical easterlies in southern Africa's winter rainfall zone during the Holocene. QSRv 107, 138-148.

546 Chase, B.M., Meadows, M.E., 2007. Late Quaternary dynamics of southern Africa's winter rainfall zone. Earth-Sci. Rev. 84, 103-138.

548 Chase, B.M., Meadows, M.E., Carr, A.S., Reimer, P.J., 2010. Evidence for progressive Holocene aridification in southern Africa recorded in Namibian hyrax middens: implications for African Monsoon dynamics and the "African Humid Period". QuRes 74, 36-45.

Chase, B.M., Meadows, M.E., Scott, L., Thomas, D.S.G., Marais, E., Sealy, J., Reimer, P.J., 2009. A record of rapid Holocene climate change preserved in hyrax middens from southwestern Africa. Geo 37, 703-706.

554 Chase, B.M., Quick, L.J., Meadows, M.E., Scott, L., Thomas, D.S.G., Reimer, P.J., 2011.

555 Late glacial interhemispheric climate dynamics revealed in South African hyrax middens.

556 Geo 39, 19-22.

557 Chase, B.M., Scott, L., Meadows, M.E., Gil-Romera, G., Boom, A., Carr, A.S., Reimer, P.J., 558 Truc, L., Valsecchi, V., Quick, L.J., 2012. Rock hyrax middens: a palaeoenvironmental archive for southern African drylands. QSRv 56, 107-125.

560 Chevalier, M., Chase, B.M., 2015. Southeast African records reveal a coherent shift from

561 high- to low-latitude forcing mechanisms along the east African margin across last glacial562 interglacial transition. QSRv 125, 117-130.

563 Chevalier, M., Chase, B.M., 2016. Determining the drivers of long-term aridity variability: a southern African case study. JQS 31, 143-151.

565 Clark, P.U., Dyke, A.S., Shakun, J.D., Carlson, A.E., Clark, J., Wohlfarth, B., Mitrovica, 566 J.X., Hostetler, S.W., McCabe, A.M., 2009. The Last Glacial Maximum. Sci 325, 710-714.

567 Clarkson, C., Petraglia, M., Korisettar, R., Haslam, M., Boivin, N., Crowther, A., Ditchfield, 568 P., Fuller, D., Miracle, P., Harris, C., Connell, K., James, H., Koshy, J., 2009. The oldest and 
longest enduring microlithic sequence in India: 35000 years of modern human occupation and change at the Jwalapuram Locality 9 rockshelter. Antiquity 83, 326-348.

Cleghorn, N., Marean, C.W., 2004. Distinguishing selective transport and in situ attrition: a critical review of analytical approaches. J Taphon 2, 43-67.

Coe, M.J., Cumming, D.H., Phillipson, J., 1976. Biomass and production of large African herbivores in relation to rainfall and primary production. Oecologia 22, 341-354.

Cowling, R., 1983. Phytochorology and vegetation history in the south-eastern Cape, South

576 Africa. J. Biogeogr. 10, 393-419.

577 Deacon, H.J., 1979. Excavations at Boomplaas Cave : a sequence through the Upper 578 Pleistocene and Holocene in South Africa. Wld. Archaeol. 10, 241-257.

579 Deacon, H.J., Deacon, J., Scholtz, A., Thackeray, J.F., Brink, J.S., 1984. Correlation of 580 palaeoenvironmental data from the Late Pleistocene and Holocene deposits at Boomplaas 581 Cave, southern Cape, in: Vogel, J.C. (Ed.), Late Cainozoic Palaeoclimates of the Southern 582 Hemisphere. Balkema, Rotterdam, pp. 339-360.

583 Deacon, J., 1972. Wilton: An assessment after fifty years. S. Afr. Archaeol. Bull. 27, 10-48.

584 Deacon, J., 1978. Changing patterns in late Pleistocene / early Holocene prehistory in 585 southern Africa as seen from the Nelson Bay Cave stone artifact sequence. QuRes 10, 84586111.

587 Deacon, J., 1982. The Later Stone Age in the southern Cape, South Africa. University of 588 Cape Town, Cape Town, South Africa.

589 Deacon, J., 1984. The Later Stone Age in southernmost Africa. Archaeopress, Oxford.

590 Deacon, J., Lancaster, N., 1988. Late Quaternary palaeoenvironments of southern Africa. 591 Clarendon Press, Oxford.

592 Delagnes, A., Schmidt, P., Douze, K., Wurz, S., Bellot-Gurlet, L., Conard, N.J., Nickel, K.G., 593 van Niekerk, K.L., Henshilwood, C.S., 2016. Early Evidence for the Extensive Heat 594 Treatment of Silcrete in the Howiesons Poort at Klipdrift Shelter (Layer PBD, 65 ka), South 595 Africa. PLoS One 11, e0163874.

596 East, R., 1984. Rainfall, soil nutrient status and biomass of large African savanna mammals. 597 Afr. J. Ecol. 22, 245-270.

598 Ehleringer, J.R., Cooper, T.A., 1988. Correlations between carbon isotope ratio and 599 microhabitat of desert plants. Oecologia 76, 562-566.

600 Elston, R.G.-., Brantingham, P.J., 2002. Microlithic technology in Northern Asia: A risk601 minimizing strategy of the Late Paleolithic and Early Holocene, in: Elston, R.G., Kuhn, S.L. 602 (Eds.), Thinking Small: Global Perspectives on Microlithization.

603 Faith, J.T., 2007. Changes in reindeer body part representation at Grotte XVI, Dordogne, 604 France. J. Archaeol. Sci. 34, 2003-2011.

605 Faith, J.T., 2011a. Late Pleistocene climate change, nutrient cycling, and the megafaunal 606 extinctions in North America. QSRv 30, 1675-1680.

607 Faith, J.T., 2011b. Late Quaternary Megafaunal Extinctions in Southern Africa's Cape Floral 608 Region, Department of Anthropology. The George Washington University. 
609 Faith, J.T., 2013a. Taphonomic and paleoecological change in the large mammal sequence

610 from Boomplaas Cave, Western Cape, South Africa. J. Hum. Evol. 65, 715-730.

611 Faith, J.T., 2013b. Ungulate diversity and precipitation history since the Last Glacial

612 Maximum in the Western Cape, South Africa. QSRv 68, 191-199.

613 Faith, J.T., Behrensmeyer, A.K., 2013. Climate change and faunal turnover: testing the 614 mechanics of the turnover-pulse hypothesis with South African fossil data. Palb 39, 609-627.

615 Faith, J.T., Thompson, J.C., in press. Low-survival skeletal elements track attrition, not 616 carcass transport behavior in Quaternary large mammal assemblages, in: Giovas, C.M., 617 LeFebre, M. (Eds.), Zooarchaeology in Practice: Case Studies in Methodology and 618 Interpretation in Archaeofaunal Analysis. Springer.

619 Farmer, E.C., deMenocal, P.B., Marchitto, T.M., 2005. Holocene and deglacial ocean 620 temperature variability in the Benguela upwelling region: implications for low-latitude 621 atmospheric circulation. PalOc 20, doi:10.1029/2004PA001049.

622 Farquhar, G.D., Ehleringer, J.R., Hubick, K.T., 1989. Carbon isotope discrimination and 623 photosynthesis. Annu. Rev. Plant Physiol. Plant Mol. Biol. 40, 503-537.

624 Farquhar, G.D., Richards, R.A., 1984. Isotopic composition of plant carbon correlates with 625 wtaer-use efficiency of wheat genotypes. Aust. J. Plant Physiol. 11, 539-552.

626 Fischer, H., Fundel, F., Ruth, U., Twarloh, B., Wegner, A., Udisti, R., Becagli, S., Castellano, 627 E., Morganti, A., Severi, M., Wolff, E., Littot, G., Röthlisberger, R., Mulvaney, R., Hutterli, 628 M.A., Kaufmann, P., Federer, U., Lambert, F., Bigler, M., Hansson, M., Jonsell, U., de 629 Angelis, M., Boutron, C., Siggaard-Andersen, M.-L., Steffensen, J.P., Barbante, C., Gaspari, 630 V., Gabrielli, P., Wagenbach, D., 2007. Reconstruction of millennial changes in dust 631 emission, transport and regional sea ice coverage using the deep EPICA ice cores from the 632 Atlantic and Indian Ocean sector of Antarctica. E\&PSL 260, 340-354.

633 Foley, R.A., Lahr, M.M., 2003. On stony ground: Lithic technology, human evolution, and 634 the emergence of culture. Evol Anthropol 12, 109-122.

635 Goebel, T., 2002. The "Microblade Adaptation" and recolonization of Siberia during the Late 636 Upper Pleistocene, in: Elston, R.G., Kuhn, S.L. (Eds.), Thinking Small: Global Perspectives 637 on Microlithization.

638 Grosjean, M., Cartajena, I., Geyh, M.A., Nunez, L., 2003. From proxy data to paleoclimate 639 interpretation: the mid-Holocene paradox of the Atacama Desert, northern Chile. 640 Palaeogeogr., Palaeoclimatol., Palaeoecol. 194, 247-258.

641 Hames, R.B., 1992. Time allocation, in: Smith, E.A., Winterhalder, B. (Eds.), Evolutionary 642 Ecology and Human Behavior. Aldine de Gruyter, New York, pp. 203-235.

643 Handley, L.L., Austin, A.T., Stewart, G.R., Robinson, D., Scrimgeour, C.M., Raven, J.A., 644 Heaton, T.H.E., Schmidt, S., 1999. The ${ }^{15} \mathrm{~N}$ natural abundance $\left(\delta^{15} \mathrm{~N}\right)$ of ecosystem samples 645 reflects measures of water availability. Funct. Plant Biol. 26, 185-199.

646 Handley, L.L., Odee, D., Scrimgeour, C.M., 1994. $\delta^{15} \mathrm{~N}$ and $\delta^{13} \mathrm{C}$ patterns in savanna 647 vegetation: dependence on water availability and disturbance. Funct. Ecol. 8, 306-314.

648 Hartman, G., 2011. Are elevated $\delta^{15} \mathrm{~N}$ values in herbivores in hot and arid environments 649 caused by diet or animal physiology? Funct. Ecol. 25, 122-131. 
650 Heaton, T.H.E., 1987. The ${ }^{15} \mathrm{~N} /{ }^{14} \mathrm{~N}$ ratios of plants in South Africa and Namibia: relationship 651 to climate and coastal/saline environments. Oecologia 74, 236-246.

652 Heaton, T.H.E., Talma, A.S., Vogel, J.C., 1986. Dissolved gas paleotemperatures and ${ }^{18} \mathrm{O}$ 653 variations derived from groundwater near Uitenhage, South Africa. QuRes 25, 79-88.

654 Henshilwood, C., d'Errico, F., Vanhaeren, M., Van Niekerk, K., Jacobs, Z., 2004a. Middle 655 Stone Age shell beads from South Africa. Sci 304, 404.

656 Henshilwood, C.S., d'Errico, F., Vanhaeren, M., van Niekerk, K., Jacobs, Z., 2004b. Middle 657 Stone Age shell beads from South Africa. Sci 384, 404.

658 Henshilwood, C.S., d'Errico, F., Yates, R., Jacobs, Z., Tribolo, C., Duller, G.A.T., Mercier, 659 N., Sealy, J.C., Valladas, H., Watts, I., Wintle, A.G., 2002. Emergence of modern human 660 behavior: Middle Stone Age engravings from South Africa. Sci 295, 1278-1280.

661 Henshilwood, C.S., van Niekerk, K.L., Wurz, S., Delagnes, A., Armitage, S.J., Rifkin, R.F., 662 Douze, K., Keene, P., Haaland, M.M., Reynard, J., Discamps, E., Mienies, S.S., 2014. 663 Klipdrift Shelter, southern Cape, South Africa: Preliminary Report on the Howiesons Poort 664 layers. J. Archaeol. Sci. 45, 284-303.

665 Hogg, A.G., Hua, Q., Blackwell, P.G., Niu, M., Buck, C.E., Guilderson, T.P., Heaton, T.J., 666 Palmer, J.G., Reimer, P.J., Reimer, R.W., Turney, C.S.M., Zimmerman, S.R.H., 2013. 667 SHCal13 Southern Hemisphere Calibration, 0-50,000 Years cal BP.

668 Kim, J.-H., Schneider, R.R., 2003. Low-latitude control of interhemispheric sea-surface 669 temperature contrast in the tropical Atlantic over the past 21 kyrs: the possible role of SE 670 trade winds. ClDy 23, 337-347.

671 Klein, R.G., 1972. The late Quaternary mammalian fauna of Nelson Bay Cave (Cape 672 Province, South Africa): its implications for megafaunal extinctions and environmental and 673 cultural change. QuRes 2, 135-142.

674 Klein, R.G., 1980. Environmental and ecological implications of large mammals from Upper 675 Pleistocene and Holocene sites in southern Africa. Ann. S. Afr. Mus., 223-283.

676 Klein, R.G., 1983. Palaeoenvironmental implications of Quaternary large mammals in the 677 Fynbos region, in: Deacon, H.J., Hendey, Q.B. and Lambrechts, J.J.N. (Ed.), Fynbos 678 Palaeoecology: a preliminary synthesis, 75 ed, pp. 116-138.

679 Kohfeld, K.E., Graham, R.M., de Boer, A.M., Sime, L.C., Wolff, E.W., Le Quéré, C., Bopp, 680 L., 2013. Southern Hemisphere westerly wind changes during the Last Glacial Maximum: 681 paleo-data synthesis. QSRv 68, 76-95.

682 Kuhn, S.L., 1995. Mousterian Lithic Technology. Princeton University Press, Princeton.

683 Kuhn, S.L., Clark, A.E., 2015. Artifact densities and assemblage formation: Evidence from 684 Tabun Cave. J. Anthrop. Archaeol. 38, 8-16.

685 Levine, J.G., Yang, X., Jones, A.E., Wolff, E.W., 2014. Sea salt as an ice core proxy for past 686 sea ice extent: a process-based model study. Journal of Geophysical Research: Atmospheres $687119,5737-5756$.

688 Loftus, E., Sealy, J., Lee-Thorp, J., 2016. New Radiocarbon Dates and Bayesian Models for 689 Nelson Bay Cave and Byneskranskop 1: Implications for the South African Later Stone Age 690 Sequence. Radiocarbon FirstView, 1-17. 

P., 2012. South African and Lesotho Stone Age sequence updated. S. Afr. Archaeol. Bull. 67, $120-144$.

694 Lowe, J.J., Rasmussen, S.O., Björck, S., Hoek, W.Z., Steffensen, J.P., Walker, M.J.C., Yu, Z.C., 2008. Synchronisation of palaeoenvironmental events in the North Atlantic region during the Last Termination: a revised protocol recommended by the INTIMATE group. QSRv 27, 6-17.

698 Mackay, A., 2009. History and Selection in the Late Pleistocene Archaeology of the Western 699 Cape, South Africa, School of Archaeology and Anrthopology. Australian National 700 University.

Mackay, A., Marwick, B., 2011. Costs and benefits of technological decision making under variable conditions: Examples from the late Pleistocene in southern Africa, in: Marwick, B., Mackay, A. (Eds.), Keeping your Edge: Recent Approaches to the Organisation of Stone Artefact Technology. Archaeopress, Oxford, pp. 119-134.

Mackay, A., Stewart, B.A., Chase, B.M., 2014. Coalescence and fragmentation in the late Pleistocene archaeology of southernmost Africa. J. Hum. Evol. 72, 26-51.

Marean, C.W., 2010. Pinnacle Point Cave 13B (Western Cape Province, South Africa) in context: The Cape Floral kingdom, shellfish, and modern human origins. J. Hum. Evol. 59, 425-443.

710 Marean, C.W., 2014. The origins and significance of coastal resource use in Africa and 711 Western Eurasia. J. Hum. Evol. 77, 17-40.

712 Marean, C.W., Cawthra, H.C., Cowling, R.M., Esler, K.J., Fisher, E., Milewski, A., Potts, 713 A.J., Singels, E., De Vynck, J., 2014. Stone Age people in a changing South African Greater Cape Floristic Region, in: N. Allsopp, Colville, J.F., Verboom, G.A. (Eds.), Fynbos: Ecology, Evolution, and Conservation of a Megadiverse Region. Oxford University Press, Oxford, UK, pp. 164-199.

717 McCall, G.S., 2007. Behavioral ecological models of lithic technological change during the 718 later Middle Stone Age of South Africa. J. Archaeol. Sci. 34, 1738-1751.

719 McCall, G.S., Thomas, J.T., 2012. Still Bay and Howiesons Poort Foraging Strategies: 720 Recent Research and Models of Culture Change. Afr. Archaeol. Rev. 29, 7-50.

721 McManus, J.F., Francois, R., Gherardi, J.-M., Keigwin, L.D., Brown-Leger, S., 2004. 722 Collapse and rapid resumption of Atlantic meridional circulation linked to deglacial climate 723 changes. Nature 428, 834-837.

724 Mellars, P., 2006. Why did modern human populations disperse from Africa ca. 60,000 years ago? A new model. Proc. Natl. Acad. Sci. U.S.A. 103, 9381-9386.

726 Metcalfe, D., Jones, K.T., 1988. A Reconsideration of Animal Body-Part Utility Indices. 727 Amer. Antiq. 53, 486-504.

728 Mitchell, P., 2000. The organisation of Later Stone Age lithic technology in the Caledon 729 Valley, Southern Africa. Afr. Archaeol. Rev. 17, 141-176.

730 Mitchell, P.J., 1988. The early microlithic assemblages of southern Africa. BAR, Oxford.

731 Moffett, R.O., Deacon, H.J., 1977. The Flora and Vegetation in the Surrounds of Boomplaas 732 

Scientific Publications, Oxford.

735

736

737

738

739

740

741

742

743

744

Mucina, L., Rutherford, M.C., 2006. The vegetation of South Africa, Lesotho and Swaziland, Strelitzia. South African National Biodiversity Institute, Pretoria.

Murphy, B.P., Bowman, D.M.J.S., 2006. Kangaroo metabolism does not cause the relationship between bone collagen $\delta^{15} \mathrm{~N}$ and water availability. Funct. Ecol. 20, 1062-1069.

Murphy, B.P., Bowman, D.M.J.S., 2009. The carbon and nitrogen isotope composition of Australian grasses in relation to climate. Funct. Ecol. 23, 1040-1049.

Neeley, M.P., 2002. Going microlithic: A Levantine perspective on the adoption of microlithic technologies, in: Elston, R.G., Kuhn, S.L. (Eds.), Thinking Small: Global Perspectives on Microlithization.

Pargeter, J., 2016. Lithic miniaturization in Late Pleistocene southern Africa. Journal of Archaeological Science: Reports 10, 221-236.

Parkington, J., Cartwright, C., Cowling, R.M., Baxter, A., Meadows, M., 2000. Palaeovegetation at the Last Glacial Maximum in the Western Cape, South Africa: wood charcoal and pollen evidence from Elands Bay Cave. SAJSc 96, 543-546.

Parry, W.J., Kelly, R.L., 1987. Expedient core technology and sedentism, in: Johnson, J.K., Morrow, C.A. (Eds.), The organization of core technology. Westview Press, pp. 285-304.

Partridge, T.C., Scott, L., Hamilton, J.E., 1999. Synthetic reconstructions of southern African environments during the Last Glacial Maximum (21-18 kyr) and the Holocene Altithermal (8-6 kyr). Quat Int 57-8, 207-214.

Partridge, T.C., Scott, L., Schneider, R.R., 2004. Between Agulhas and Benguela: responses of southern African climates of the late Pleistocene to current fluxes, orbital precession and the extent of the circum-Antarctic vortex, Past Climate Variability through Europe and Africa, pp. 45-68.

Pate, J.S., 2001. Carbon isotope discrimination and plant water-use efficiency: case scenarios for $\mathrm{C}_{3}$ plants, in: Unkovich, M., Pate, J., McNeill, A., Gibbs, D.J. (Eds.), Stable Isotope Techniques in the Study of Biological Processes and Functioning of Ecosystems. Kluwer Academic Publishers, Dordrecht, pp. 19-37.

Petraglia, M., Clarkson, C., Boivin, N., Haslam, M., Korisettar, R., Chaubey, G., Ditchfield, P., Fuller, D., James, H., Jones, S., Kivisild, T., Koshy, J., Lahr, M.M., Metspalu, M., Roberts, R., Arnold, L., 2009. Population increase and environmental deterioration correspond with microlithic innovations in South Asia ca. 35,000 years ago. Proc Natl Acad Sci U S A 106, 12261-12266.

Powell, A., Shennan, S., Thomas, M.G., 2009. Late Pleistocene demography and the appearance of modern human behavior. Sci 324, 1298-1301.

Quick, L.J., Carr, A.S., Meadows, M.E., Boom, A., Bateman, M.D., Roberts, D.L., Reimer, P.J., Chase, B.M., 2015. A late Pleistocene-Holocene multi-proxy record of palaeoenvironmental change from Still Bay, southern Cape Coast, South Africa. JQS 30, 870885 .

Quick, L.J., Meadows, M.E., Bateman, M.D., Kirsten, K.L., Mäusbacher, R., Haberzettl, T., Chase, B.M., 2016. Vegetation and climate dynamics during the last glacial period in the 
fynbos-afrotemperate forest ecotone, southern Cape, South Africa. Quat Int 404, Part B, 136149.

Riel-Salvatore, J., Barton, M., 2004. Late Pleistocene Technology, Economic Behavior, and Land-Use Dynamics in Southern Italy. Amer. Antiq. 69, 257-274.

Roberts, P., Henshilwood, C.S., van Niekerk, K.L., Keene, P., Gledhill, A., Reynard, J.,

780 Badenhorst, S., Lee-Thorp, J., 2016. Climate, environment and early human innovation: stable isotope and faunal proxy evidence from archaeological Sites (98-59ka) in the Southern Cape, South Africa. PLoS One 11, e0157408.

783 Rutherford, M.C., Mucina, L., Powrie, L.W., 2012. The South African National Vegetation Database: History, development, applications, problems and future. SAJSc 108.

Rutherford, M.C., Powrie, L.W., Midgley, G.F., 2003. ACKDAT: A digital spatial database of distributions of South African plant species and species assemblages. S. Afr. J. Bot. 69, 99-104.

788 Sale, J.B., 1965. The feeding behaviour of rock hyraces (genera Procavia and Heterohyrax) 789 in Kenya. Afr. J. Ecol. 3, 1-18.

790 SANBI, 2003. PRECIS (National Herbarium Pretoria (PRE) Computerized Information 791 System) database.

792 Scholtz, A., 1986. Palynological and Palaeobotanical Studies in the Southern Cape. 793 University of Stellenbosch, Stellenbosch, South Africa.

794 Schweitzer, F.R., Wilson, M.L., 1983. Byneskranskop 1: A late Quaternary living site in the 795 southern Cape province, South Africa. The Rustica Press, Cape Town.

796 Scott, L., 1982. Late Quaternary fossil pollen grains from the Transvaal, South Africa. Rev. 797 Palaeobot. Palynol. 36, 241-278.

798 Sealy, J., Lee-Thorp, J., Loftus, E., Faith, J.T., Marean, C.W., 2016. Late Quaternary 799 environmental change in the Southern Cape, South Africa, from stable carbon and oxygen 800 isotopes in faunal tooth enamel from Boomplaas Cave. JQS 31, 919-927.

801 Sime, L.C., Kohfeld, K.E., Le Quéré, C., Wolff, E.W., de Boer, A.M., Graham, R.M., Bopp, 802 L., 2013. Southern Hemisphere westerly wind changes during the Last Glacial Maximum: 803 model-data comparison. QSRv 64, 104-120.

804 Smith, B.N., 1972. Natural abundance of the stable isotopes of carbon in biological systems. 805 BioSc 22, 226-231.

806 Stiner, M.C., Munro, N.D., Surovell, T.A., 2000. The tortoise and the hare: small-game use, 807 the broad spectrum revolution, and Paleolithic demography. Curr. Anthrop. 41, 39-73.

808 Stocker, T.F., 1998. The seesaw effect. Sci 282, 61-62.

809 Stocker, T.F., Johnsen, S.J., 2003. A minimum thermodynamic model for the bipolar seesaw. $810 \quad$ PalOc 18.

811 Stockmarr, J., 1971. Tablets with spores used in absolute pollen analysis. Pollen et Spores 13, $812 \quad 614-621$.

813 Stone, A.E.C., 2014. Last Glacial Maximum conditions in southern Africa: are we any closer 814 to understanding the climate of this time period? Progress in Physical Geography. 
815 Stuut, J.-B.W., Crosta, X., Van der Borg, K., Schneider, R.R., 2004. On the relationship

816 between Antarctic sea ice and southwestern African climate during the late Quaternary. Geo

817 32, 909-912.

818 Talma, A.S., Vogel, J.C., 1992. Late Quaternary paleotemperatures derived from a 819 speleothem from Cango Caves, Cape Province, South Africa. QuRes 37, 203-213.

820 van Zinderen Bakker, E.M., 1953. South African pollen grains and spores. Part I. Balkema, 821 Amsterdam/Cape Town.

822 van Zinderen Bakker, E.M., 1956. South African pollen grains and spores. Part II. Balkema, 823 Amsterdam/Cape Town.

824 van Zinderen Bakker, E.M., Coetzee, J.A., 1959. South African pollen grains and spores. Part 825 III. Balkema, Amsterdam/Cape Town.

826 Vogel, J.C., 1978. Isotopic assessment of the dietary habits of ungulates. SAJSc 74, 298-301.

827 Wadley, L., 1993. The Pleistocene Later Stone Age south of the Limpopo River. Journal of 828 World Prehistory 7, 243-296.

829 Wang, L., D'Odorico, P., Ries, L., Macko, S.A., 2010. Patterns and implications of plant-soil $830 \quad \delta^{13} \mathrm{C}$ and $\delta^{15} \mathrm{~N}$ values in African savanna ecosystems. QuRes 73, 77-83.

831 Wilkins, J., Brown, K.S., Oestmo, S., Pereira, T., Ranhorn, K.L., Schoville, B.J., Marean, 832 C.W., 2017. Lithic technological responses to Late Pleistocene glacial cycling at Pinnacle 833 Point Site 5-6, South Africa. PLoS One 12, e0174051.

834 Will, M., Mackay, A., 2016. What factors govern the procurement and use of silcrete during 835 the Stone Age of South Africa? Journal of Archaeological Science: Reports.

836 Wolff, E.W., Barbante, C., Becagli, S., Bigler, M., Boutron, C.F., Castellano, E., de Angelis, 837 M., Federer, U., Fischer, H., Fundel, F., Hansson, M., Hutterli, M., Jonsell, U., Karlin, T., 838 Kaufmann, P., Lambert, F., Littot, G.C., Mulvaney, R., Röthlisberger, R., Ruth, U., Severi, 839 M., Siggaard-Andersen, M.L., Sime, L.C., Steffensen, J.P., Stocker, T.F., Traversi, R., 840 Twarloh, B., Udisti, R., Wagenbach, D., Wegner, A., 2010. Changes in environment over the 841 last 800,000 years from chemical analysis of the EPICA Dome C ice core. QSRv 29, 285842295.

\section{Table Captions}

845 Table 1: Zooarchaeological indicators of foraging efficiency at Boomplaas Cave. These include the 846 relative abundance of tortoises (\%), leporids (\%), and mean food utility index (FUI) of high-survival 847 body parts belonging to size 3-4 mammals.

848 Table 2: The correlation (Spearman's $\rho$ ) between lithic technological indicators and faunal 849 community composition (DCA Axis 1 scores) for ungulates and microfauna at Boomplaas Cave. 850 Significant values in bold.

851 Figure Captions 
852 Figure 1: (A) Map of southern Africa showing seasonality of rainfall and climatic gradients dictated 853 by the zones of summer/tropical (orange) and winter/temperate (blue) rainfall dominance. Winter 854 rainfall is primarily a result of frontal systems embedded in the westerly storm track. Major 855 atmospheric (white arrows) and oceanic (blue arrows) circulation systems and the austral summer 856 positions of the Inter-Tropical Convergence Zone (ITCZ) and the Congo Air Boundary (CAB) are 857 indicated. The location of the study site in the transitional southern Cape region is shown. (B) Map of 858 southwest African coastal region with the Seweweekspoort sites and other key palaeoenvironmental 859 and archaeological sites indicated (shading as for panel 'A'). (C) Topographical map of 860 Seweweekspoort, with the SWP-1 and SWP-3 sites indicated.

861 Figure 2: Comparison of $\delta^{15} \mathrm{~N}(\mathrm{e}), \delta^{13} \mathrm{C}$ values (b), fynbos (c) and grass (d) pollen percentages from 862 the Seweweekspoort hyrax middens with relevant palaeoenvironmental records including the northern 863 summer rainfall zone wet season precipitation reconstruction (a; Chevalier and Chase, 2015), the 864 Bermuda Rise record of Atlantic Meridional Overturning Circulation (AMOC) strength and the 865 northward oceanic transport of heat (f; McManus et al., 2004), foraminifera records indicating 866 conditions in the ocean to the south of the Africa (g, h; Barker et al., 2009) and sea salt sodium 867 concentrations from the EPICA DML ice core in Antarctica (i; Fischer et al., 2007).

868 Figure 3: Comparison of $\delta^{15} \mathrm{~N}(\mathrm{j})$ and $\delta^{13} \mathrm{C}$ (i) values from the Seweweekspoort hyrax middens with 869 zooarchaeological records (a-c) of macrofauna (Faith, 2013a; Klein, 1983) and microfauna (Avery, 870 1982), and (d-h) lithic data (Deacon, 1979; Deacon et al., 1984) from Boomplaas Cave. Error bars on 871 the data from Boomplaas reflect potential age ranges $(2 \sigma)$ of each stratigraphic unit. 